\title{
Characterization and Comparison of Biodiesels Made from Korean Freshwater Algae
}

\author{
Injoon Yeo, ${ }^{\dagger}$ Jieun Jeong, ${ }^{\dagger}$ Yunju Cho,${ }^{\dagger}$ Jiwon Hong, ${ }^{\dagger}$ Ho-Sung Yoon, ${ }^{\dagger}$ Sung Hong Kim,,${ }^{\S}$ and Sunghwan Kim ${ }^{\dagger, \#, *}$ \\ †Kyungpook National University, Department of Chemistry, Daegu 702-701, Korea. *E-mail: sunghwank@knu.ac.kr \\ Kyungpook National University, Department of Bio-chemistry, Daegu 702-701, Korea \\ ${ }^{\S}$ Korea Basic Science Institute, Daegu Center, Daegu 702-701, Korea. *E-mail: sunghkim@kbsi.re.kr \\ ${ }^{*}$ Green-Nano Materials Research Center, Daegu 702-701, Korea \\ Received April 19, 2011, Accepted July 8, 2011
}

Key Words : Alga, Prokaryote, Eukaryote, Hydrocarbon, Fatty acid

Biofuels, including biodiesel, are an attractive replacement for petroleum diesel because they are renewable and compatible with existing diesel engines. Biodiesel can be made from oils extracted from a variety of materials ranging from soybeans to algae. Algae in particular has gained considerable interest in recent years because it yields more oil per hectare than any other crop. ${ }^{1}$ However, one of the major bottlenecks in the large-scale production of algae biodiesel is low conversion efficiency. To improve the efficiency with which algae can be processed into biodiesel, one must fully understand the chemical composition of the raw materials. The alkane and alkene compounds in algae are particularly interesting because these classes of compounds comprise the major constituents in gasoline and jet fuels. Previous studies have reported the presence of various hydrocarbons in algae, ${ }^{2-7}$ but these findings have been controversial. ${ }^{8}$ In addition, while several studies have indicated the presence of hydrocarbons in prokaryotic algae (cyanobacterium), ${ }^{2-7}$ relatively few studies have examined eukaryotic algae.

Although many studies have investigated the chemical composition of algae biodiesels in general, ${ }^{9,10}$ few reports have characterized biodiesels made from domestic Korean algae. Domestic algae harvesting and biodiesel production are important in terms of both cultivation and conversion efficiencies. The current study characterized the chemical compositions of biodiesels made from two prokaryotic and one eukaryotic freshwater algae. The algae used in this study are commonly found in the wild in Korea. The hydrocarbon content of the samples depended greatly on the alga species.

\section{Experimental Section}

Collection and Cultivation of Domestic Algae. Three algae samples including Nostoc sp. KNUA003, Limnothrix sp. KNUA012, and Chlamydomonas moewusii KNUA013 were used in this study. Nostoc and Limnothrix are cyanobacteria, while Chlamydomonas is a eukaryotic alga. Nostoc was originally isolated from Lake Daecheong (Chu-dong, Dong-gu, Daejeon, South Korea, $\left.36^{\circ} 22^{\prime} \mathrm{N}, 127^{\circ} 28^{\prime} \mathrm{E}\right)$ in September 2009. Limnothrix was isolated from Lake Hapcheon (Bongsan-myeon, Hapcheon-gun, Gyeongsangnamdo, South Korea, $35^{\circ} 37^{\prime} \mathrm{N}, 128^{\circ} 02^{\prime} \mathrm{E}$ ) in September 2010.
Chlamydomonas was isolated from an indoor raceway pond at Kyungpook National University (Sankyuk-dong, Buk-gu, Daegu, South Korea, 35 53'N, 128 36'E) in November 2010. Each seed culture was inoculated in an 18-L, transparent, polycarbonate bottle containing $16 \mathrm{~L}$ of a 1:500 dilution of a commercial liquid fertilizer (BioNex; 5.1\% N, 10\% $\mathrm{P}_{2} \mathrm{O}_{5}$, and $5 \% \mathrm{~K}_{2} \mathrm{O}$; Biosangsa, Busan, South Korea). The cultures were autotrophically grown at $25^{\circ} \mathrm{C}$ with a flow of air bubbles at approximately $2 \mathrm{~L} \mathrm{~min}^{-1}$ under cool fluorescent lighting (approximately $70 \mu$ mole $\mathrm{m}^{-2} \mathrm{~s}^{-1}$ ) with a light:dark cycle of 16:8 h. After a 2-week incubation period, the algal cells were harvested by centrifugation at $3,220 \times g$ for 10 min and stored at $-70{ }^{\circ} \mathrm{C}$.

Extraction, Transesterification, and Biodiesel Extraction. The harvested algae were rinsed with clean water and freeze-dried to enhance extraction efficiencies. ${ }^{17}$ One gram of each dried sample was mixed with a mixture of chloroform:methanol (2:1) according to the method described by Bligh and Dryer ${ }^{18}$ and placed in a separation funnel. The extraction was performed overnight. After extraction, the chloroform extract was isolated and dried with a rotary evaporator. The dried extract was treated with a premade solution of methanol and potassium hydroxide to facilitate transesterification. ${ }^{19}$ Twenty milliliters of hexane was also added to the mixture to help isolate the biodiesel. The whole mixture was heated to $30{ }^{\circ} \mathrm{C}$ and stirred for $10 \mathrm{~h}$. After $10 \mathrm{~h}$, the mixture was cooled and the methanol and hexane layers were separated. The yellow hexane layer was isolated for further analyses.

Gas Chromatography. Detailed chemical compositions of the biodiesels were derived from GC/MS experiments. The mass spectrometer was a Jeol JMS700 equipped with an Agilent $6890 \mathrm{~N}$ gas chromatograph (GC) with a DB-5 capillary column $(30 \mathrm{~m} \times 0.25 \mathrm{~mm}$ ID $\times 0.25 \mu \mathrm{m}$ film thickness; Agilent Technologies, Palo Alto, CA, USA). The initial GC oven temperature of $100{ }^{\circ} \mathrm{C}$ was maintained for $2 \mathrm{~min}$, increased to $250{ }^{\circ} \mathrm{C}$ at a rate of $10{ }^{\circ} \mathrm{C} \mathrm{min}{ }^{-1}$, and held at $250{ }^{\circ} \mathrm{C}$ for $10 \mathrm{~min}$. The injection size was $1 \mu \mathrm{L}$ with a split ratio of 20:1. Helium was used as the carrier gas at a constant flow rate of $1 \mathrm{~mL} \mathrm{~min}$. The injector and MS source temperatures were $280{ }^{\circ} \mathrm{C}$ and $250{ }^{\circ} \mathrm{C}$, respectively. In electron impact (EI) mode, an acceleration voltage of $70 \mathrm{eV}$ was used for sample ionization, and the scanning range went 


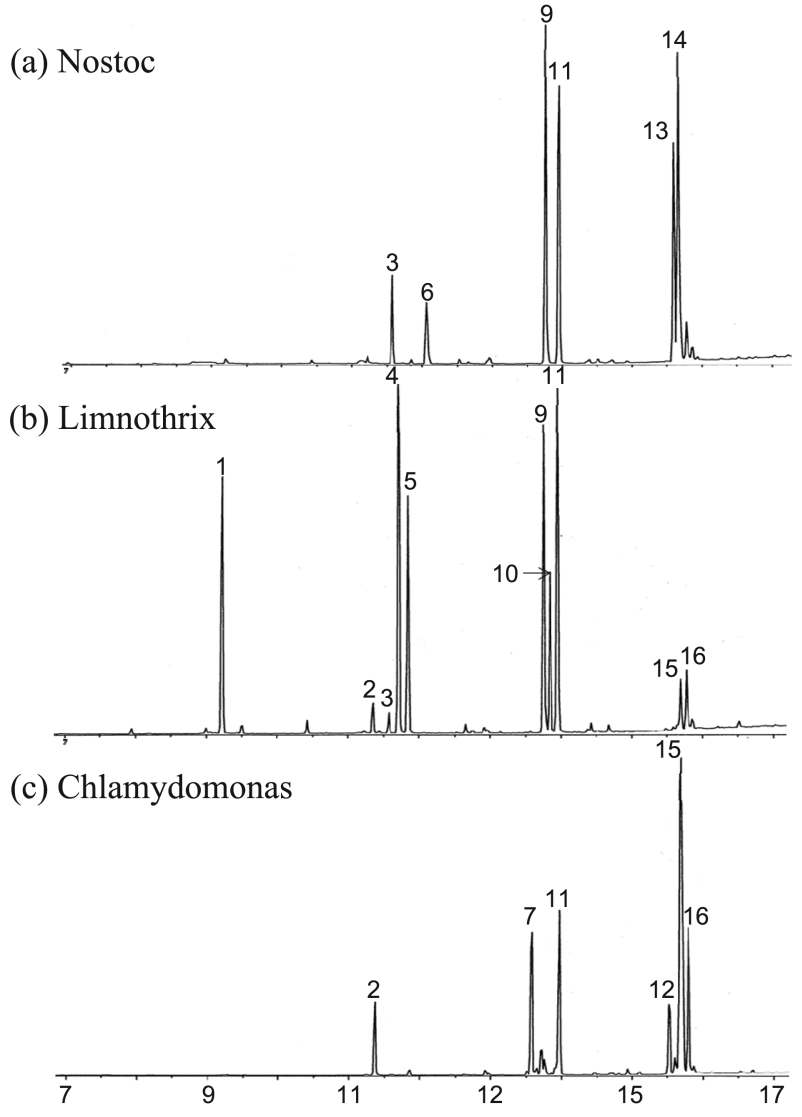

Figure 1. Total ion chromatograms of biodiesels made from (a) Nostoc sp. KNUA003, (b) Limnothrix sp. KNUA012, and c) Chlamydomonas moewusii KNUA013.

from $40 \mathrm{amu}$ to $400 \mathrm{amu}$. NIST libraries were used as reference databases.

Total ion chromatographs (TICs) obtained by GC-MS analyses of three biofuels, each made from the separate prokaryotic and eukaryotic algae, are shown in Figure 1. The spectra contain a total of 17 prominent peaks. Peak identification and compound assignment was based on electron impact (EI) MS spectra. EI-MS spectra of the selected peaks and diagrams of proposed fragmentation patterns are provided in Figure 2. Molecular ions are clearly shown for the identified compounds. The identified compounds and their chemical structures are listed in Table 1. The chromatographs in Figure 1 and the list of compounds in Table 1 show that hydrocarbons, fatty acid methyl esters, and alcohols make up a significant fraction of biofuels derived from either eukaryotic or prokaryotic algae.

The data in Table 1 show that only 4 out of the 17 compounds were common to all three samples. The composition and relative abundance of the various compounds differed significantly depending on species. For example, monoenoic hydrocarbons were found in the biodiesel made form Chlamydomonas and Limnothrix. Unsaturated hydrocarbons are known to be produced by algae,,$^{4-5,11}$ and saturated hydrocarbons were identified in Nostoc and Limnothrix. These types of compounds are the major
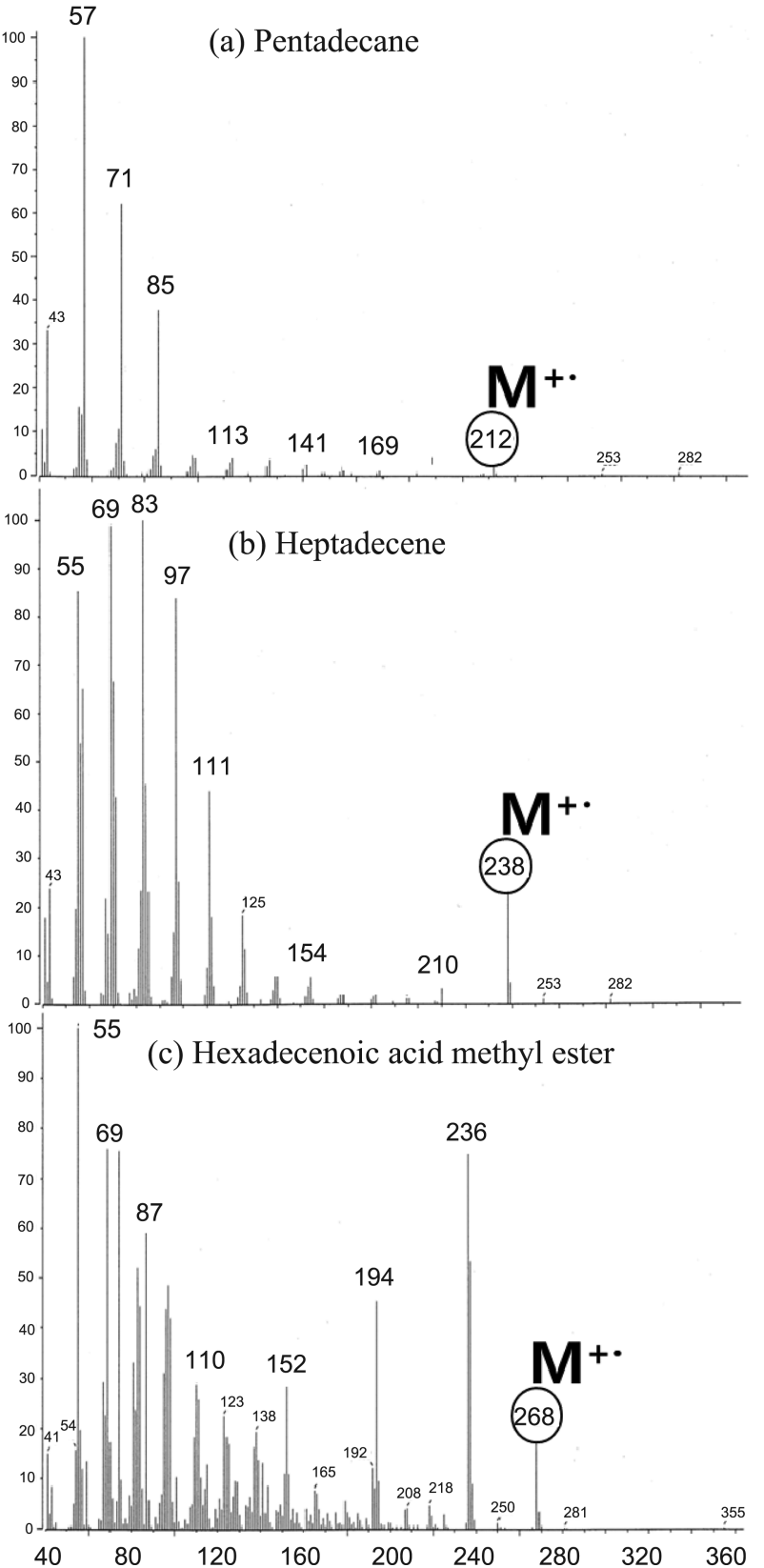

Figure 2. Examples of electron impact mass spectra of (a) pentadecane, (b) 1-heptadecene, and (c) hexadecenoic methyl ester identified from the biodiesel TICs in Figure 1.

constituents of liquid fuels (e.g., gasoline and diesel) and may therefore be important for biofuel production. The biosynthetic pathway for alkanes in cyanobacteria was recently identified and reported. ${ }^{12}$ Three of the hydrocarbons found in this study (peaks 1,2, and 3) contained an odd number of carbon atoms. The production of alkanes in microorganisms is reported to occur via decarboxylation of fatty acids, ${ }^{13}$ and removal of the carboxylic functional group from an even-numbered fatty acid results in an odd-numbered alkane.

A mono-branched alkane was identified in Nostoc, and similar results have been reported previously. ${ }^{14,15}$ Han and 
Table 1. List of compounds identified in algae. (N; Nostoc sp. KNUA003, L; Limnothrix sp. KNUA012, C; Chlamydomonas moewusii KNUA013)

\begin{tabular}{|c|c|c|c|c|c|c|}
\hline No. & Compound name & Molecular formula & Molecular weight & $\mathrm{N}$ & $\mathrm{L}$ & $\mathrm{C}$ \\
\hline 1 & Pentadecane & $\mathrm{C}_{15} \mathrm{H}_{32}$ & 212 & & $\sqrt{ }$ & \\
\hline 2 & 1-Heptadecene & $\mathrm{C}_{17} \mathrm{H}_{34}$ & 238 & & $\sqrt{ }$ & $\sqrt{ }$ \\
\hline 3 & $n$-Heptadecane & $\mathrm{C}_{17} \mathrm{H}_{36}$ & 240 & $\sqrt{ }$ & $\sqrt{ }$ & \\
\hline 4 & 1-Tetradecenoic acid methyl ester (C14:1) & $\mathrm{C}_{15} \mathrm{H}_{28} \mathrm{O}_{2}$ & 240 & & $\sqrt{ }$ & \\
\hline 5 & $n$-Tetradecanoic acid methyl ester & $\mathrm{C}_{15} \mathrm{H}_{30} \mathrm{O}_{2}$ & 242 & & $\sqrt{ }$ & \\
\hline 6 & Methylheptadecane & $\mathrm{C}_{18} \mathrm{H}_{38}$ & 254 & $\sqrt{ }$ & & \\
\hline 7 & Hexadecatetraenoic acid methyl ester(C16:4) & $\mathrm{C}_{17} \mathrm{H}_{26} \mathrm{O}_{2}$ & 262 & & & $\sqrt{ }$ \\
\hline 8 & Hexadecatrienoic acid methyl ester (C16:3) & $\mathrm{C}_{17} \mathrm{H}_{28} \mathrm{O}_{2}$ & 264 & & & $\sqrt{ }$ \\
\hline 9 & $n$-Hexadecenoic acid methyl ester (C16:1) & $\mathrm{C}_{17} \mathrm{H}_{32} \mathrm{O}_{2}$ & 268 & $\sqrt{ }$ & $\sqrt{ }$ & $\sqrt{ }$ \\
\hline 10 & $n$-Hexadecenoic acid methyl ester (C16:1) & $\mathrm{C}_{17} \mathrm{H}_{32} \mathrm{O}_{2}$ & 268 & & $\sqrt{ }$ & \\
\hline 11 & $n$-Hexadecanoic acid methyl ester (C16:0) & $\mathrm{C}_{17} \mathrm{H}_{34} \mathrm{O}_{2}$ & 270 & $\sqrt{ }$ & $\sqrt{ }$ & $\sqrt{ }$ \\
\hline 12 & Octadecatetraenoic acid methyl ester (C18:4) & $\mathrm{C}_{19} \mathrm{H}_{30} \mathrm{O}_{2}$ & 290 & & & $\sqrt{ }$ \\
\hline 13 & Octadecadienoic acid methyl ester (C18:2) & $\mathrm{C}_{19} \mathrm{H}_{34} \mathrm{O}_{2}$ & 294 & $\sqrt{ }$ & & $\sqrt{ }$ \\
\hline 14 & Octadecatrienoic acid methyl ester (C18:3) & $\mathrm{C}_{19} \mathrm{H}_{32} \mathrm{O}_{2}$ & 292 & $\sqrt{ }$ & & $\sqrt{ }$ \\
\hline 15 & $n$-Octadecenoic acid methyl ester (C18:1) & $\mathrm{C}_{19} \mathrm{H}_{36} \mathrm{O}_{2}$ & 296 & & $\sqrt{ }$ & $\sqrt{ }$ \\
\hline 16 & Tetramethylhexadecenol & $\mathrm{C}_{20} \mathrm{H}_{40} \mathrm{O}_{1}$ & 296 & $\sqrt{ }$ & $\sqrt{ }$ & $\sqrt{ }$ \\
\hline 17 & $n$-Octadecanoic acid methyl ester (C18:0) & $\mathrm{C}_{19} \mathrm{H}_{38} \mathrm{O}_{2}$ & 298 & $\sqrt{ }$ & & \\
\hline
\end{tabular}

Calvin ${ }^{14}$ suggested that mono-branched alkanes are generated by a series of alkylation and decarboxylation reactions with unsaturated fatty acids. Therefore, one may reasonably expect that the mono-branched alkane compound identified in this study has an even number of carbon atoms. Additionally, the hydrocarbons identified in this study contained between 15 and 17 carbon atoms; no heavier hydrocarbons were identified. ${ }^{11,16}$

The fatty acid methyl ester distribution of Limnothrix was unique; fatty acid methyl esters containing 14 and 16 carbon atoms were the most prevalent compounds with a relatively minor amount of an 18-carbon fatty acid methyl ester. In contrast, the major components in biodiesels from Chlamydomonas and Nostoc were 16- and 18-carbon fatty acid methyl esters. Neither of these samples contained any 14carbon fatty acid methyl esters. In Limnothrix, a lower carbon number distribution for fatty acids may be closely related to the lower carbon numbers observed for its hydrocarbon compounds.

In summary, this report details the chemical compositions of biodiesels generated from domestic Korean algae. Various compounds, including alkanes, branched alkanes, alkenes, and fatty acid methyl esters, were identified. The biofuel composition varied significantly with the alga species. This study shows that freshwater algae can be a valuable hydrocarbon source.

Acknowledgments. This work was supported by the Korea Research Council of Fundamental Science and Technology (KRCF) through Basic Research Project managed by the Korea Research Institute of Standards and
Science (KRISS) and KBSI grant to S. Kim.

\section{References}

1. Mata, T. M.; Martins, A. N. A.; Caetano, N. S. Renew. Sust. Energ. Rev. 2010, 14, 217-232.

2. Han, J.; Chan, H. W. S.; Calvin, M. J. Am. Chem. Soc. 1969, 91, 5156-5159.

3. Blumer, M.; Guillard, R. R. L.; Chase, T. Mar. Biol. 1971, 8, 183189.

4. Youngblood, W. W.; Blumer, M.; Guillard, R. L.; Fiore, F. Mar. Biol. 1971, 8, 190-201.

5. Youngblood, W. W.; Blumer, M. Mar. Biol. 1973, 21, 163-172.

6. Tornabene, T. G. Experientia 1982, 38, 43-46.

7. Bhadauriya, P.; Gupta, R.; Singh, S.; Bisen, P. S. World $J$ Microbiol Biotechnol 2008, 24, 139-141.

8. Wackett, L. P.; Frias, J. A.; Seffernick, J. L.; Sukovich, D. J.; Cameron, S. M. Appl. Environ. Microbiol 2007, 73, 7192-7198.

9. Vijayaraghavan, K.; Hemanathan, K. Energ. Fuel. 2009, 23, 54485453.

10. Fedosova, S. N.; Braskb, J.; Xua, X. J. Chrom. A 2011, in press.

11. Gelpi, E.; Oro, J.; Schneider, H. J.; Bennett, E. O. Science 1968 , 161, 700-701.

12. Schirmer, A.; Rude, M. A.; Li, X.; Popova, E.; Cardayre, S. B. D. Science 2010, 329, 559-562.

13. Mcinnes, A. G.; Walter, J. A.; Wright, J. L. C. Lipids 1979, 15, 609-615.

14. Han, J.; Calvin, M. Chem. Comm. 1970, 1490-1491.

15. Koster, J.; Volkman, J. K.; Rullkotter, J.; Scholz-Bottcher, B. M.; Rethmeier, J.; Fischer, U. Org. Geochem. 1999, 30, 1367-1379.

16. Winters, K.; Parker, P. L.; Baalen, C. V. Science 1969, 163, 467468.

17. Zhu, M.; Zhou, P. P.; Yu, L. J. Bioresour. Technol. 2002, 84, 93-95.

18. Bligh, E. G.; Dyer, W. J. Can. J. Biochem. Physiol. 1959, 3, 911-917.

19. Burja, A. M.; Armenta, R. E.; Radianingtyas, H.; Barrow, C. J. J. Agric. Food Chem. 2007, 55, 4795-4801. 